\title{
A Demographic Study of the Multidimensional Poverty of Women in India
}

\author{
Ramya Rachel S. \\ Assistant Professor, Research Centre and \\ Department of Economics, Lady Doak College, Madurai, India
}

\section{Abstract}

Foremost in the Sustainable Development Goals (SGDs) of the 2030 Agenda, is the goal of achieving "No Poverty". With nearly a decade yet to go, it is imperative to know the true nature and extent of poverty so that steps can be taken to eradicate poverty in all its forms. Multidimensional Poverty is a problem that persists on a larger extent in a developing country such as India, particularly among its women. The study uses the Demographic Health Survey data - India's National Family Health Survey (NFHS), a nationwide survey conducted with a representative sample of women aged 15 to 49 throughout the country, to shed light on the nature and extent of deprivations faced by them. The deprivations faced by the women are measured along the dimensions of education, health and standard of living as per the global Multidimensional Poverty Index (MPI) jointly developed by UNDP (United Nations Development Program) and Oxford Poverty and Human Development Initiative (OPHI). Findings reveal that one-fifth of women in India are multidimensionally poor. Further subgroup decomposition reveals that higher levels of deprivations are found in women living alone, with higher age, having more number of children, widowed or divorced, husbands having multiple wives, those having more than one union and married before the legal age of marriage. The Government needs to focus its attention on the most deprived groups of women. Based on the nature and the extent of deprivations that they face, appropriate measures must be taken to bring them out of their destitution.

Keywords: multidimensional poverty, deprivations, sub-group decomposition, Indian women

\section{Introduction}

A life without dearth of wants and needs is the ultimate goal of every individual. Still, millions of people struggle for a life without deprivation of basic needs. The first goal of the 2030 Agenda of the Sustainable Development Goals is to achieve "No Poverty". 
With a decade yet to go, it is imperative to know whether nations are equipped with the right tools to eradicate poverty from its roots. It is necessary for Governments to realise the true nature of poverty, its incidence and intensity by measuring poverty in a way which can reflect the plight of people. Policy responses to eradicate the problem should take a multidisciplinary approach addressing the basic necessities of humans such as education, health care and access to proper living conditions. It shifts the focus of analysing poverty from a monetary perspective to reflect the livelihood of the poor based on their education, health and standard of living. According to estimates of the 2018 global Multidimensional Poverty Index released by the United Nations Development Program (UNDP) and the Oxford Poverty and Human Development Initiative (OPHI), in 2015-16, within a decade, India halved its poverty rate. But it still houses the second largest amount of the world's poor. (UNDP, 2018)

Women in developing countries are more likely to be poor than men (OXFAM), particularly in a patriarchal society. In a country with more than three-fourth of its women being economically dependent on men, (Dixon, 2018) there arises a need to view poverty through a gendered lens. The household level approach to studying poverty assumes that all family members' incomes and resources contribute to the well-being of every individual in the household (World Bank Institute, 2005). It seldom projects the gender inequality in allocation of economic resources, particularly in access to education and proper health care. The deprivations that women in the working-age face must be brought into light as they have children to support, particularly when their access to economic resources are limited. Therefore, the study seeks to understand the nature of poverty of women aged between 15 to 49 from a demographic perspective.

\section{Background}

Eradicating poverty has been the focus of many policies taken by the Government but its successful accomplishment has been uncertain. The World Bank defines Poverty as "low incomes and the inability to acquire the basic goods and services necessary for survival with dignity. Poverty also encompasses low levels of health and education, poor access to clean water and sanitation, inadequate physical security, lack of voice, and insufficient capacity and opportunity to better one's life." Basically, poverty is the deprivation of many imminent needs.

As the approach to poverty has become multifaceted, its measurement has, in many dimensions, gathered momentum. Studies on multidimensional poverty show that the income poverty misses out on the deprivations that the poor face. A study by Wang, Fang, Xia and Alkire on the rural households in China (Xiaolin Wang, 2016) shows that, according to the national poverty line, 67.79 per cent of poor households are lifted out of income poverty but they are in vulnerable (28 per cent) or ordinary (38 per cent) or extreme ( 1.69 per cent) multidimensional poverty. Therefore, in poverty identification, income can hardly capture the comprehensiveness and 
complexity of poverty. Hence, multidimensional measurement is vital not only to know the level of poverty, but also to understand its nature.

The dimensions of poverty to be studied must be declared clearly. Studies on multidimensional poverty have focussed on the level of education attained by the women as a measure of poverty. A substantial poverty reduction can be made when the household members are educated. A study on education and poverty has found that as the level of education lowers, the poverty level becomes higher (Bici, 2017). The health of women also is a significant concern, the deprivation of which would lead to a detrimental condition of life. Studies show that the health of the women have been declining over the years. Women need to have good health so that they can support their families better. Studies also show a high correlation between the health and the level of poverty of women (Ngoma, 2017). Standard of living also is a good indicator of poverty. A household earning enough to feed a family but living under a leaking roof would mean that the household is under poverty.

Since the basic needs for survival are multiple in numbers, it is an outright necessity to check if the number of people who face that deprivation is worrisome. Therefore, it is important to study the dimensions of education, health and standard of living with respect to demographic factors to measure the poverty of women and identify the ones in imminent need of policy action. The present study focuses on studying the deprivations faced by women on these aspects. Past studies' focus on demographic variables as factors of multidimensional poverty is very limited. The study therefore overcomes this research gap and analyses the multidimensional poverty among various demographic sub-groups.

The objectives of the study are to

know the deprivations faced by the women aged between 15 and 49 in India

find the incidence and intensity of multidimensional poverty among the women

analyse the multidimensional poverty of the women in India among various demographic sub-groups

identify critical sub-groups of women that face high level of multidimensional poverty

\section{Methodology}

The study uses the Demographic Health Survey data - India's National Family Health Survey (NFHS), a nationwide survey conducted with a representative sample of households throughout the country. A total of 628,900 households were selected for the sample, out of which, interviews were completed with 699,686 women aged 1549. The global Multidimensional Poverty Index (MPI) jointly developed by UNDP (United Nations Development Program) and Oxford Poverty and Human development Initiative (OPHI) has been used to measure multidimensional poverty of these women. STATA /IC 16 was used to analyse the data from the survey. The 
deprivations faced by the women are measure along the dimensions of education, health and standard of living. The indicators selected under each dimension have been outlined in figure 1. Equal weights are given for each dimension. The indicators under each dimension were also given equal weights. Weighted deprivation scores will be calculated for the women. If the deprivation score is one-third or above, the women are under multidimensional poverty.

Figure 1: Composition of MPI - Dimensions and Indicators

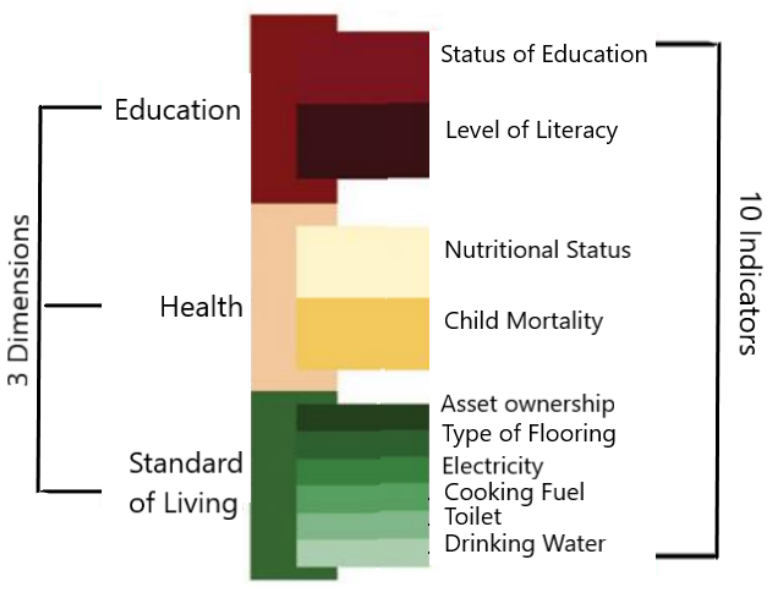

Source: Global MPI of UNDP and OPHI - modified for study

The global MPI has been used to measure poverty with few changes. The dimension of education in the global MPI entails their educational attainment and literacy, where the woman is deprived if she has no education and cannot read or write respectively. Studies show that these two do not go hand in hand and that a considerable number of women who were educated could not read or write. They are equally important to assess the level of education of women. In the dimension of health, the indicators of women's deprivation include nutritional status, i.e., Body Mass Index is less than 18.5 $\mathrm{kg} / \mathrm{m}^{2}$ and Child mortality i.e., they have lost sons or daughters. The dimension of Standard of living includes Asset Ownership i.e. women's household has less than 2 small assets - TV, radio, fridge, bike, motor, telephone and no car/truck, Type of Flooring i.e. household has a dirt, sand or dung floor, availability of electricity, Cooking fuel i.e. dung, wood, charcoal or coal is used as cooking fuel, availability of improved toilets and availability of improved drinking water i.e. no access to improved drinking water or if water is at more than 30 minutes' walk.

Alkire Foster method has been used to measure the incidence and intensity of Multidimensional Poverty. (Alkire, 2011) The women are classified as multidimensionally poor and non-poor on the basis of their weighted deprivation scores. The incidence is expressed as the multidimensional headcount ratio $(\mathrm{H})$ : 
$\mathrm{H}=\frac{q}{n}$

Here $\mathrm{q}$ is the number of people who are multidimensionally poor and $\mathrm{n}$ is the total population. It is the proportion of women under multidimensional poverty.

The intensity of poverty (A) is the average deprivation score of the multidimensionally poor people and can be expressed as:

$$
A=\frac{\sum_{i=1}^{n} c_{i}(k)}{q}
$$

Here, $c_{i}(k)$ is the censored deprivation score of individual $\mathrm{i}$ and $\mathrm{q}$ is the number of people who are multidimensionally poor. The MPI is the product of both: MPI $=\mathrm{H} \times \mathrm{A}$.

After the MPI is calculated, the deprivations of the non-poor will be censored as the focus is on the women who are multidimensionally poor i.e., the sum of weighted deprivation score of each indicator is one-third or more of total possible deprivations. On this ground, the incidence of poverty can be explained by the Censored Headcount Ratio, which is the proportion of women who are poor and deprived in each of the indicators. It also shows an accurate magnitude of deprivation of the poor in each indicator.

The contribution of each indicator to the MPI has also been calculated to identify the area of deprivation that needs immediate policy attention. The percentage contribution of each indicator to MPI is calculated as:

$$
\text { Contribution of indicator } i \text { to } M P I=\frac{w_{i} C H_{i}}{M P I} * 100
$$

Here $\mathrm{w}_{\mathrm{i}}$ is the weight of indicator $\mathrm{i}$ and $\mathrm{CH}_{\mathrm{i}}$ is the censored headcount ratio of indicator i. Whenever the contribution of an indicator is higher than its weight, this suggests that there is a relative high deprivation of this indicator. The poor are more deprived in this indicator than the others.

MPI then is decomposed by population sub-groups of age, religion, marital status, and family size and the number of children, to find out the level of incidence and intensity of poverty among the sub-groups.

Furthermore, the incidence of multidimensional poverty has been analysed for specific critical demographic sub-groups of women to understand the development issues faced by these women. Critical sub-groups have more than 50 per cent of the population under multidimensional poverty. The factors considered for critical subgroup analysis include demographic factors such as age, family structure and role, marital status and fertility preferences. 


\section{Findings and Discussions}

\section{Deprivations Faced by Women}

Women experience adverse livelihood conditions in developing countries. The amount of deprivations they face often goes unnoticed or ignored. The study has found the level of deprivation faced by the women in India in each indicator.

\section{Deprivations in the Dimension of Education}

\section{Status of Educational Attainment}

The study finds that in India, 27.59 per cent of the women aged 15 to 49 are deprived of any education at all. Women are burdened in a society that does not recognise their need for basic education on the assumption that their role resides inside the walls of the house and that they will be economically dependent on their partners. In a country where such a notion is widespread, women tend to have lesser access to the means to get a life-sustaining employment when the economic need arises. Women's education is not given its due importance in such a condition and these families do not educate girls if they cannot afford it or just because the educational institution is too far away. They would rather vouch for her a better living if they can marry her off to a family by paying a sufficient dowry.

\section{Level of Literacy}

It is also a matter of concern that 31.62 per cent of the women do not know how to read or write. Women are trained from a young age to assist their family with the household chores but not in learning or doing well in schools. There is an urgent need to improve the literacy of women so that they are neither deprived nor cheated of anything and so that they are empowered to participate in the decision making for the household.

Figure 2: Deprivations faced by women aged 15 to 49 in India

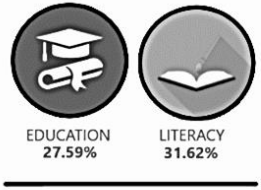

EDUCATION

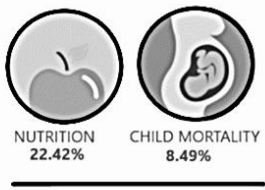

HEALTH

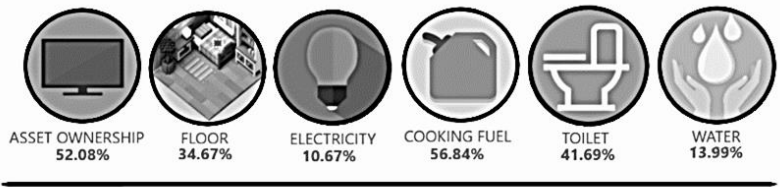

STANDARD OF LIVING

Source: NFHS 2015-16

\section{Deprivations in the Dimension of Health}

\section{Level of Nutrition}

The health conditions of the women also need to be taken into account. Women with poor health conditions will not be able to perform their day-to-day duties with ease. 
Finding shows that 22.42 per cent of the women have a Body Mass Index of less than $18.5 \mathrm{~kg} / \mathrm{m}^{3}$. According to the World Health Organisation, these women are malnourished. Poor physical health among adults leads to adverse health outcomes in future which translates into a poor standard of living. Working aged women need better nutrition in order to function at their homes, workplaces and in the society. Malnutrition hampers the efforts of women at various aspects of their lives.

\section{Child Mortality}

Child mortality is a major problem faced but the level of deprivation is relatively low compared to other indicators. About 10 per cent of women have lost sons or daughters. Studies have shown higher levels of child mortality among poor women (WHO, 2019). This has been attributed towards unaffordability and inaccessibility to proper health care facilities and also due to the inattention to health care and unconcerned health seeking behaviour of the women.

\section{Deprivations in the Dimensions of Standard of Living}

\section{Standard of Living}

Many women do not have a proper standard of living. Women in poverty are subject to a lower standard of living. Many women live in unsuitable housing conditions and do not have any access or ownership to assets. Policy decisions must ensure decent living conditions of women as a right to have adequate standard of living including access to nutritious food, clean water, proper cooking fuel, electricity and toilets.

Asset Ownership: 52 per cent of women do not have access to basic consumer durables such as TV, radio, fridge, bike, motor, telephone and no car/truck. Moreover, an additional finding reveals that a staggering sixty per cent of households of the women do not have ownership to neither a house nor land. Among the households that own house(s) or land, only 27.9 per cent of women do not have joint ownership and own house(s) or land alone.

Flooring: The type of flooring is an indicator of poverty as dirt floors reflects the inability and unaffordability of household to get a proper cemented flooring. Findings reveal that 34.67 per cent of women still live in houses that have dirt floors.

Electricity: Poor households do not have proper access to electricity and electrification does not necessarily ensure that there are no frequent blackouts and maintenance problems. Despite the Government's measures to bring affordable electricity to low economic households, study finds that ten per cent of the households do not have access to electricity.

Cooking Fuel: It is appalling to find that still more than half of women cook with dung, wood, charcoal or coal. They cannot afford an LPG cylinder. 
Availability of Toilet: There are no improved toilets of nearly 40 per cent of the women's households. Improper sanitation facilities need to be checked to ensure health and hygiene amongst the members of the family.

Availability of drinking water: Deprivation of water resources is also a major problem faced in developing countries. Many households do not have access to clean and safe drinking water, leading to constraints on a healthy lifestyle. Study finds that 14 per cent of Indian women face a dearth of drinking water. Even if drinking water is available, these women need to travel for more than 30 minutes to get the water.

On the whole, the study finds that women face high levels of deprivation of basic necessities. The deprivations the women face have been outlined in figure 2 . The women face the highest levels of deprivation in cooking fuel and in the ownership of assets like TV and radio.

\section{Incidence and Intensity of Multidimensional Poverty}

\section{How many are poor?}

Using Alkire-Foster Methodology, the Headcount Ratio $(\mathrm{H})$ has been calculated. The percentage of women aged 15 to 49 under Multidimensional Poverty has been found to be 38.44. These women have deprivations in one-third or more of the indicators. More than one-third of the total women aged 15 to 24 in India are multidimensionally poor.

Figure 3: Incidence of Multidimensional Poverty among Women in India aged 15-49

\section{Percentage of Women under Multidimensional Poverty}

Headcount

38.45
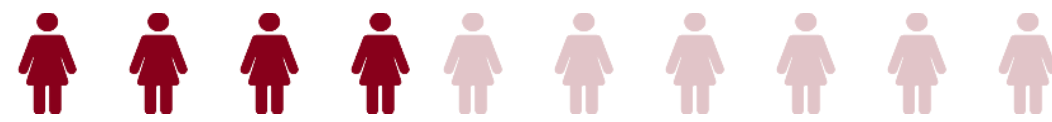

Source: NFHS 2015-16

\section{How poor are they?}

It is important to understand the amount of deprivation the poor women face. The intensity of deprivations faced by women paints a clear picture on this aspect. The intensity of multidimensional poverty has been found by the average deprivations that the MPI poor women face. On an average, the multidimensionally poor women are deprived in 52.53 per cent of the weighted indicators.

\section{Level of Multidimensional Poverty}

Therefore, taking into account the depth of poverty, the MPI $\left(\mathrm{M}_{0}\right)$ has been estimated to be 20.19 per cent which shows that the multidimensionally poor women face 20 
per cent of all deprivations if all women aged 15 to 49 were poor and deprived in all dimensions and indicators. The proportion of weighted deprivations the poor women experience in society out of all the total potential deprivations that the society could experience.

\subsection{Sub-Group Decomposition of the Multidimensional Poverty of Women}

\section{Who is poor?}

In order to identify who the poor are, the poverty of the women in the study has been decomposed into various demographic sub-groups. The classifications are based on age, religion, marital status, and family structure. The incidence and intensity of Multidimensional Poverty among the women aged 15 to 49 have been calculated and shown in Table 2. This shows the level and depth of poverty among each group of the population.

Table 2: Incidence and Intensity of Multidimensional Poverty among Women

\begin{tabular}{|c|c|c|c|c|}
\hline BASIS & CLASSIFICATION & $\begin{array}{l}\text { INCIDENC } \\
\text { E: } \\
\text { Headcount }\end{array}$ & $\begin{array}{l}\text { INTENSITY: } \\
\text { Average } \\
\text { Deprivation }\end{array}$ & $\begin{array}{l}\text { MPI: } \\
\text { Adjusted } \\
\text { Headcount }\end{array}$ \\
\hline \multirow{3}{*}{ Age } & 15 to 24 & 27.35 & 46.89 & 12.82 \\
\hline & 25 to 40 & 40.38 & 54.4 & 21.97 \\
\hline & 41 to 49 & 54.16 & 54.28 & 29.4 \\
\hline \multirow{5}{*}{ Religion } & Hindu & 39.16 & 52.88 & 20.71 \\
\hline & Muslim & 40.26 & 51.36 & 20.68 \\
\hline & Christian & 22.9 & 50.11 & 11.47 \\
\hline & Other religions & 20 & 45.38 & 9.08 \\
\hline & No religion & 46.74 & 55.54 & 25.96 \\
\hline \multirow{5}{*}{$\begin{array}{l}\text { Marital } \\
\text { Status }\end{array}$} & never in union & 22.85 & 43.75 & 9.99 \\
\hline & married & 42.37 & 53.91 & 22.84 \\
\hline & widowed & 58.93 & 54.34 & 32.03 \\
\hline & divorced & 38.11 & 52.75 & 20.1 \\
\hline & $\begin{array}{l}\text { no longer living } \\
\text { together }\end{array}$ & 50.04 & 52.89 & 26.47 \\
\hline \multirow{8}{*}{$\begin{array}{l}\text { Size of } \\
\text { the } \\
\text { Family }\end{array}$} & 1 & 56.09 & 55.42 & 31.09 \\
\hline & 2 & 43.6 & 53.37 & 23.27 \\
\hline & 3 & 35.02 & 52.09 & 18.24 \\
\hline & 4 to 5 & 35.59 & 52.19 & 18.57 \\
\hline & 6 to 10 & 42.16 & 53.02 & 22.35 \\
\hline & $>10$ & 38.17 & 51.31 & 19.59 \\
\hline & 0 & 24.92 & 46.1 & 11.49 \\
\hline & 1 & 28.32 & 51.63 & 14.62 \\
\hline
\end{tabular}




\begin{tabular}{|l|l|l|l|l|}
\multirow{4}{*}{$\begin{array}{l}\text { Number } \\
\text { of }\end{array}$} & 2 & 33.03 & 51.5 & 17 \\
\cline { 2 - 5 } children & 3 & 54.29 & 53.98 & 29.3 \\
\cline { 2 - 5 } & 4 & 69.84 & 56.57 & 39.51 \\
\cline { 2 - 5 } & 5 & 81.07 & 59.04 & 47.86 \\
\cline { 2 - 5 } & $>5$ & 89.45 & 60.11 & 53.77 \\
\hline
\end{tabular}

Source: NFHS 2015-16

\section{Decomposition based on Age}

Women aged 15 to 49 have been classified as young adults (15 to 24), adults (25 to 40 ) and middle aged (41 to 49). The findings indicate that the incidence of poverty is higher among the ages 41 to 49 . The poverty seems to be higher among women of higher age groups and they face higher levels of deprivation. 27 per cent of young women are under poverty. But the rates are much higher for the women above the age of 25. The intensity of poverty also seems to increase by age. Adjusted Headcount Ratio $\left(\mathrm{M}_{0}\right)$ has been found to be highest among the middle aged at 29.4 per cent, 22 per cent among adults and relatively low among young women at 12.83 per cent. There is an inverse relationship between age of the women and the level of multidimensional poverty.

\section{Decomposition based on Religion}

Religious beliefs, culture and customs also play a wide role when it comes to poverty. Women have different gender roles dictated by their religion whose effects on women can be seen in the form of poverty. The incidence of poverty is highest among women who do not belong to any religion. The women who belong to the religions of Hinduism and Islam face the highest amount and depth of poverty. Only 23 per cent of Christians are subject to multidimensional poverty. Women who belong to other religions like the Sikhs, Zoroastrians, Buddhists, Jain and Jews also face relatively lower incidence of poverty.

A closer look at the indicators that women were deprived of, revealed that the percentage of Hindu and Muslim women who were deprived of education was around 30 per cent in both status of education and literacy level. However, it was 16 per cent for Christian women and nearly 15 per cent for women of other religions.

\section{Decomposition based on Marital Status}

Marital Status has much to do on poverty. Women who are married face higher levels of poverty. Marital Status speaks a lot on the dependence of women as well. Among the unmarried women, 23 per cent identify as under multidimensional poverty. It is the least among women who were widowed. The intensity of poverty of women who are unmarried is the least while that of the women at married, widowed or separated is around 50 per cent. 
A closer look at the poverty level by marital status reveals that 38 per cent of women who are widows face severe poverty with deprivations more than 50 per cent and 20 per cent of widows face deprivation of 33 to 50 per cent.

\section{Decomposition based on Family Structure and Roles}

There is a high incidence of poverty on women living alone. More than half of the women living alone are under poverty with the highest intensity. As the family size gets bigger, the intensity reduces as there are more members in the family to support the family. However, this applies only if there are a greater number of adults.

Figure 4: Multidimensional Poverty by Number of Children in the Household

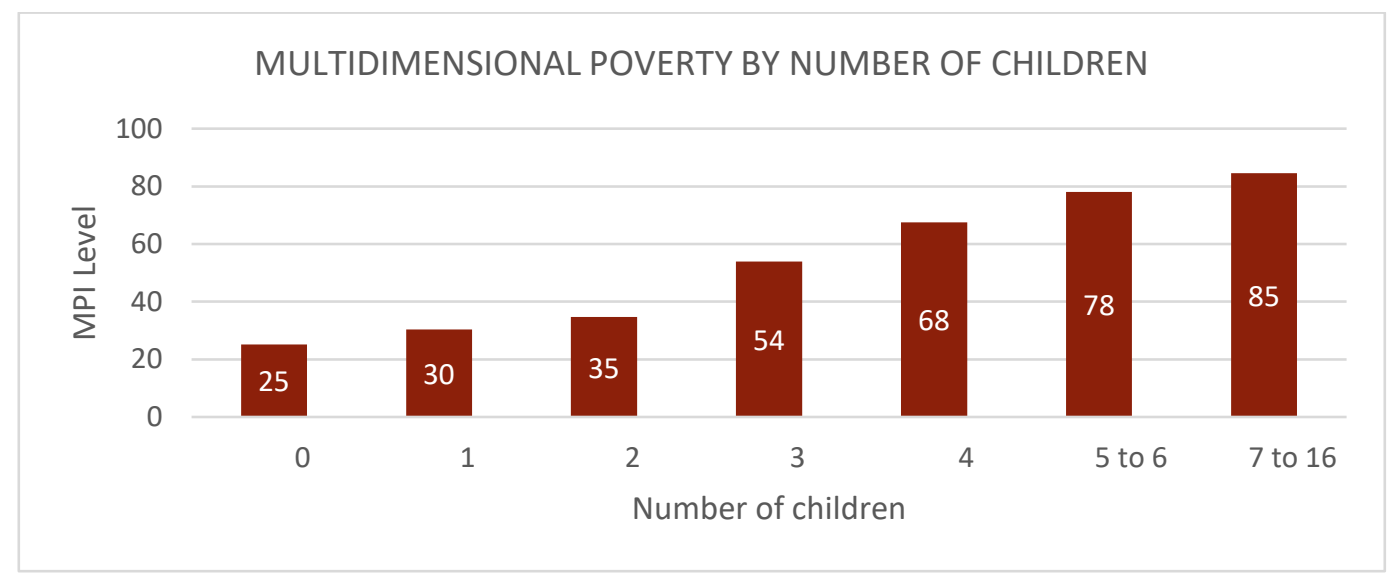

Source: NFHS 2015-16

As the number of children in the family increases, their incidence as well as the intensity of poverty has increased perpetually. When there are no children in the family, women are deprived by less than 25 per cent. Among women living with one or two children, incidence of poverty is around 30 per cent. For each child above two, the incidence of poverty amongst the households increases by more than 10 per cent. Among the households more than ten children, nearly 90 per cent live in poverty with 70 per cent under severe multidimensional poverty. These women are deprived in more than 50 per cent of total deprivations.

\subsection{Critical Sub-Groups}

The study further analysed the incidence of multidimensional poverty for specific critical demographic sub-groups of women to understand the nature of issues that hinders women's development. Critical sub-groups have more than 50 per cent of the population under multidimensional poverty. The factors considered for critical subgroup analysis include demographic factors such as age, family structure and role, marital status and fertility preferences. 
Table 3: Multidimensional Poverty among Critical Sub-groups

\begin{tabular}{|c|c|c|c|}
\hline \multicolumn{2}{|l|}{ Sub-group } & $\begin{array}{l}\text { Number of } \\
\text { Women }\end{array}$ & $\begin{array}{l}\text { Women under } \\
\text { Multidimensional Poverty }\end{array}$ \\
\hline & Age $>41$ & $\begin{array}{l}118,897 \\
(17.9)\end{array}$ & $\begin{array}{l}66,732 \\
(54.16)\end{array}$ \\
\hline & $\begin{array}{l}\text { Husband has } \\
\text { additional wives }\end{array}$ & $\begin{array}{l}7431 \\
(1.58)\end{array}$ & $\begin{array}{l}4,739 \\
(63.77)\end{array}$ \\
\hline & $\begin{array}{l}\text { More than one } \\
\text { union }\end{array}$ & $\begin{array}{l}9425 \\
(1.89)\end{array}$ & $\begin{array}{l}4912 \\
(58.55)\end{array}$ \\
\hline & $\begin{array}{l}\text { Marriage before } \\
\text { the legal age }\end{array}$ & $\begin{array}{l}268,652 \\
(56.9)\end{array}$ & $\begin{array}{l}139,489 \\
(51.92)\end{array}$ \\
\hline & Household Heads & $\begin{array}{l}37,034 \\
(5.60)\end{array}$ & $\begin{array}{l}22,283 \\
(60.17)\end{array}$ \\
\hline & Living Alone & $\begin{array}{l}2227 \\
(0.34)\end{array}$ & $\begin{array}{l}1,249 \\
(56.09)\end{array}$ \\
\hline & $\begin{array}{l}\text { Living alone with } \\
\text { children under five } \\
\text { years age }\end{array}$ & $\begin{array}{l}1647 \\
(0.25)\end{array}$ & $\begin{array}{l}984 \\
(59.57)\end{array}$ \\
\hline & Early pregnancy & $\begin{array}{l}146,418 \\
(32.43)\end{array}$ & $\begin{array}{l}80,529 \\
(55)\end{array}$ \\
\hline & $\begin{array}{l}\text { Unwanted } \\
\text { Pregnancy }\end{array}$ & $\begin{array}{l}1,539 \\
(5.23)\end{array}$ & $\begin{array}{l}885 \\
(57.47)\end{array}$ \\
\hline
\end{tabular}

Note: Figures in brackets represent percentages

Source: NFHS 2015-16

The study has identified the above categories have more than 50 per cent of women under multidimensional poverty. The highest sub-group were the women whose husbands have multiple wives with 63.8 per cent of them under poverty. The income in such a household would be diverted amongst the family and a higher proportion of these women are prone to experiencing multidimensional poverty.

Among women who had more than one union, 59 per cent were under poverty. Women in India are given in married early. They do not therefore complete their 
education and women who complete professional education stay at home if their families demand it or because they do not need it. Women who marry early before the legal age of 18 years tend to be deprived of education and also employment, making them less empowered, not only to contribute to the economic situations of the family, but also to major decisions taken in the family. More than half of married women were married before the legal age and more than half of them were under poverty.

Further analysis reveals the incidence of poverty among family structure and roles played by women bring into light certain critical sub-groups like female household heads, women who are living alone and women living with children under five years old. These women have high incidence of poverty as shown in table 6. Women living alone have no one to depend on financially and tend to fend for themselves. These women account for 0.34 per cent of women. More than half of the women living alone face deprivations of more than one-third of the indicators. Women with infants have more mouths to feed with the meagre amount of income they get. Sixty per cent of women who are living alone, with children under five years of age, have prevalence of multidimensional poverty. Such high levels of poverty need to be checked. Women with less education and low employment opportunities experience lesser quality of life as they are pushed into becoming the primary breadwinners without the resources and training needed to join the workforce. Therefore, these women who assume family roles such as the Female headed households are necessarily poorer and suffer from vulnerabilities when compared with those of male headed households (Gangopadhyay and Wadhwa, 2003). The study finds that female household heads who are these women are only 5.6 per cent of the women population, among whom sixty per cent are under poverty. Among these, only 44 per cent own houses and only 25 per cent owns land.

Fertility preference also is an important factor to identify critical sub-groups. Women with early or unwanted pregnancy are found to have a sizeable share of women under multidimensional poverty. These women at their early stages of life need to have proper livelihood and could be stuck in a poverty trap by having children early in life. Women with unintended pregnancy also tend to have higher poverty levels, with additional unplanned expenditure to meet their financial and economic needs of taking care of children.

The above identified sub-groups have higher proportion of women under multidimensional poverty and require Governmental policy action on their part to safeguard their rights to lead a decent livelihood and to ensure that they are not trapped in a never-ending cycle of poverty.

\subsection{Target Dimensions - Dimensional Breakdown of the MPI of Women Aged 15 to 49}

The women under multidimensional poverty are those whose deprivations exceed one-third of total deprivations. However, to make policy decisions, it is vital to note 
where the deprivations are the highest and which indicators constitute the most to poverty of the women. The percentage contribution of each indicator to MPI shows the perpetuation of particular indicator on the level of poverty among the women.

The study finds that literacy level is the highest contributor to the Multidimensional Poverty of women aged 15 to 49 , followed by the attainment of education. The Government must focus on providing proper education to the women. Figure 2 shows the contributions of each indicator.

Figure 5: Percentage Contribution of Indicator to the MPI of women

\title{
Percentage contribution of Indicators to MPI
}

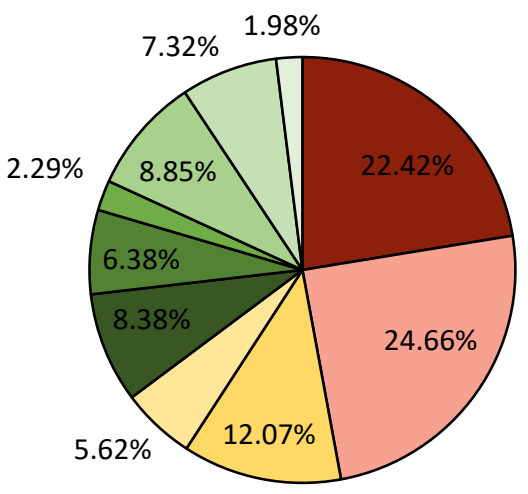

\author{
$\square$ Education \\ $\square$ Literacy level \\ $\square$ Nutrition level \\ $\square$ Child Mortality \\ $\square$ Asset Ownership \\ $\square$ Type of Flooring \\ $\square$ Availability of electricity \\ $\square$ Cooking Fuel \\ $\square$ Availability of toilet \\ $\square$ Source of drinking water
}

Source: NFHS 2015-16

Literacy and Education are the major indicators contributing to MPI followed by nutrition level. All these indicators are interrelated and have a negative impact on MPI. Higher the level of literacy and Education, higher will be the level of awareness of nutrition leading to better health conditions, thus leading to higher earning capacity, which in turn reduces the level of MPI.

The study also points out that the poor standard of living of women highly contribute to the overall MPI and is responsible for nearly 35 per cent of poverty of these women, exceeding the level of deprivations from the dimension of health i.e., the indicators of nutrition level and child mortality. This necessitates a higher and more immediate policy action on educating women and improving their living standards by a considerable amount in order to remove them from experiencing poverty in multiple dimensions.

\section{Conclusion}

Findings reveal that women in India still face high levels of deprivations in various dimensions. Shockingly, 27.59 per cent of women lack basic primary education, 31.62 
per cent do not know how to read or write, 22.42 per cent are subject to malnutrition and 8.49 per cent have sons or daughters who died. The standard of living of these women is also poor with 52.08 per cent deprived of ownership of assets, 34.67 per cent have mud or dirt floors, 10.67 per cent have no access to electricity, 56.8 per cent still cook with firewood, 41.69 per cent do not have proper sanitation facilities and 14 per cent lack proper sources of clean drinking water. Much is needed to be done by the Government and policy makers in these areas. They need to focus on empowering women by providing them access to proper education. Focus needs to be on the quality of education that they provide as the study has found that women who attend schools still do not know how to read or write basic sentences.

The level of nutrition, particularly among young women, has reached low points. Malnutrition of women has many ill-effects that manifests on the lives of the future generations. If the workforce of tomorrow is not healthy, the economic position is doomed to fail. Finally, care must be given to the standard of living of the women, especially the ones living in rural areas of the country. The development of the nation rests in the hands of its women. The Government needs to revitalise the female labour force, training them in suitable fields so that they can contribute to the household and to the society at large.

The Government needs to micromanage the bottom one per cent of the women who are under extreme poverty in order to bring them out of their destitution of all the indicators. Basic Needs analysis must be done to identify their needs and provide them the proper incentives like education and training to bring them out of poverty.

\section{References}

[1] Abraham, M. G. (2017). The poverty line is a starvation line. From Infochange India : http://infochangeindia.org/agenda-issues/hunger-foodsecurity/5662-the-poverty-line-is-a-starvation-line.html

[2] Bank, T. W. (n.d.). Poverty and Inequality Analysis. worldbank.org. From worldbank.org

[3] Dixon, Annette, (2018) “Women in India's Economic Growth", The World Bank, Accessed on 10 January 2020, Accessed at https://www.worldbank.org/en/news/speech/2018/03/17/womenindias-economic-growth

[4] Guruswamy, A. (2006). Redefining the Poverty Line in India. Public Policy Research, Volume 13, Issue 3, pp. 191-199.

[5] Jean Drèze, R. K. (2010). The BPL Census and a Possible Alternative. Economic \& Political Weekly. Volume 45, Issue No. 09.

[6] K Sundaram, S. D. (2001). NAS-NSS Estimates of Private Consumption for Poverty Estimation. Economic \& Political Weekly. Volume 36. Issue No. 02. 
[7] Santos, Alkire. (2011) The Multidimensional Poverty Index (MPI). From OPHI: https://www.ophi.org.uk/wp-content/uploads/MPI-Primer.pdf

[8] Minhas. (1970). Rural Poverty, Land Redistribution and Development Strategy: Facts and Policy. Indian Economic Review. Volume 5. Issue No. 1.

[9] OXFAM International, (n.d.). Why the Majority of World's Poor are Women. Accessed on 10 January 2020, Accessed at https://www.oxfam.org/en/whymajority-worlds-poor-are-women

[10] United Nations Development Program, (2018) "271 Million Fewer Poor People in India", Accessed on 10 January 2020, Accessed at https://www.in.undp.org/content/india/en/home/sustainabledevelopment/successstories/MultiDimesnionalPovertyIndex.html

[11] WHO. (2019) Maternal Mortality. Accessed at https://www.who.int/newsroom/fact-sheets/detail/maternal-mortality, Accessed on August 31, 2021

[12] World Bank Institute. (2005) Introduction to Poverty Analysis. Poverty Manual, All, JH Revision of August 8, 2005, pp. 71

[13] Xiaolin Wang, H. F. (2016). On the Relationship between Income Poverty and Multidimensional Poverty in China. OPHI Working Paper No. 101. 